\title{
Evidence Summary: \\ Venous leg ulcers: Exercise
}

November 2019

Author: Emily Haesler PhD, P Grad Dip Adv Nurs (Gerontics), BN

For referencing Haesler E. Evidence summary: Venous leg ulcers: Exercise. Wound Practice and Research 2019; 27(4):193-195.

DOI https://doi.org/10.33235/wpr.27.4.193-195

\section{QUESTION}

What is the best available evidence on effectiveness of exercise for healing venous leg ulcers (VLUs)?

\section{SUMMARY}

Venous leg ulcers (VLUs) are chronic wounds that occur on the lower leg due to venous disease. (Level 1).

Evidence from small clinical trials suggests that range of motion, strength and aerobic exercises (including walking) are effective in improving strength ${ }^{1}$ and flexibility. ${ }^{2}$,

3 Although there is no strong evidence that this translates to improvements in VLU healing, ${ }^{2,4-6}$ people with VLUs did experience improvements in objective measures of calf muscle pump function (e.g. ejection fraction) when they participated in exercise programs ${ }^{1,4,5}$ (Levels 1 and 2).

\section{BEST PRACTICE RECOMMENDATIONS}

Advise individuals with VLUs to engage in exercises designed to improve calf muscle pump function, in addition to compression therapy (Level B).

Recommend walking, calf muscle resistance exercise, ankle stretches and ankle circling, preferably in a supervised program, for promoting improvements in venous function. (Level B).

\section{BACKGROUND}

Venous leg ulcers occur due to venous insufficiency. Venous insufficiency describes a condition in which the venous system does not carry blood back to the heart in the most efficient manner, causing blood to pool in the veins of the lower limbs. Venous insufficiency occurs due to: ${ }^{7,8}$

- previous blood clots,

- impaired valves in the veins in the lower leg do not close sufficiently after each muscle contraction, allowing blood to flow back to a previous section of the vein (venous reflux), and

- calf muscle pump function not adequately assisting in returning blood to the heart.

Contraction and relaxation of the two calf muscles surrounding the deep veins in the leg assist in venous return. Blood pools in the veins of the legs when the calf muscles are relaxed, and contraction of the muscles compresses the veins, pushing blood back to the heart.6, 9-11 Function of the calf muscle pump requires adequate ankle motion and muscle strength to promote venous return, which is best achieved during heel-to-toe walking. ${ }^{9,11,12}$ Evidence from small studies indicates that individuals with venous disease and VLUs have inadequate calf pump muscle function, which contributes to their disease severity. ${ }^{13}$ Exercise to improve muscle strength and ankle flexibility might improve venous return. ${ }^{14}$

\section{EVIDENCE}

In most studies reported below, exercise was an adjuvant to compression therapy (Levels 1 and 2). ${ }^{1-6}$

Exercise for improving lower limb strength and flexibility

Results from clinical trials ${ }^{1-3}$ conducted in people with VLUs support the rationale that undertaking exercise can improve strength and flexibility.

\section{SOURCES OF EVIDENCE}

\begin{tabular}{|c|c|c|c|c|}
\hline Level 1 & Level 2 & Level 3 & Level 4 & Level 5 \\
\hline $\begin{array}{l}\text { Systematic reviews } \\
7,8,11,13 \\
\text { RCTs } \\
2-6,12,14\end{array}$ & $\begin{array}{l}\text { Quasi- experimental } \\
\text { studies prospectively } \\
\text { controlled } 1\end{array}$ & $\begin{array}{l}\text { Observational study } \\
\text { without a control group } \\
\text { None }\end{array}$ & None & Expert consensus 9,10 \\
\hline
\end{tabular}


A study $(n=39)^{2}$ showed that a 12-week supervised exercise program improved performance in aerobic exercises at both 3 months and 12 months. Improvements in ankle flexibility and range of movement that were achieved at 3 months were not sustained by 12 months $^{2}$ (Level 1).

A second RCT $(n=32)^{3}$ explored the impact of a program consisting of standing heel raises, ankle circling exercises, walking and stationary cycling. After 9 weeks, the exercise group had significant improvements in range of ankle dorsiflexion (mean increase $3.8^{\circ}, p<0.001$ ), plantar flexion (mean increase $4^{\circ}, p<0.001$ ) complete ankle range of motion (mean increase $8.3^{\circ}, p<0.001$ ). These results were significant $(p<0.05)$ compared with a control group that had lesser improvement in ankle flexibility ${ }^{3}$ (Level 1).

In a non-randomized trial $(\mathrm{n}=21),{ }^{1}$ people with VLUs undertook isotonic calf muscle strengthening exercises (plantar flexions performed under weight resistance). After seven days, the exercise group had a significant $135 \%$ increase in measures of calf muscle endurance $(p<0.001)^{1}$ (Level 2).

\section{Exercise for improving venous signs and symptoms}

Most of the available evidence on the effectiveness of exercise in improving venous signs and symptoms is conducted with individuals with venous disease that has not progressed to ulceration. However, there is some evidence that the findings extend to individuals with VLUs. ${ }^{1,4,5}$

One RCT $(n=21)^{4}$ evaluated progressive resistance exercises compared to no exercise program. The intervention regimen included individualised heel raise exercises that were progressively adjusted over 12 weeks. There were no significant differences between the exercise group and the no-exercise group for most measures of venous function including, venous volume, venous filling index, ejection volume, residual volume or residual volume fraction. The only measure of venous functioning that showed differences associated with heel raise exercise was ejection fraction, which improved for individuals who engaged in exercises (mean difference in change $18.5 \%, 95 \%$ confidence interval [Cl] 0.03 to $36.6 \%, \mathrm{p}<0.05)^{4}$ (Level 1).

A second RCT $(n=13)^{5}$ compared a daily exercise program of seated, standing and one-leg heel raises compared to normal care. At 12 weeks, the intervention group showed significant improvements in ejection fraction compared to baseline $(p=0.03)$ and compared to the control group $(p=0.05)^{5}($ Level 1$)$.

In the trial by Kan and Delis (2001) ${ }^{1}$ (see above), the exercise group had a significant $67.5 \%$ improvement ejection venous volume compared to baseline (median improvement $28.5 \mathrm{~mL}$, $95 \% \mathrm{Cl} 20.5$ to $35.5 \mathrm{~mL}$ ). Significant improvements were also achieved in ejection fraction $(p=0.06)$, residual venous volume $(p=0.06)$, and residual volume fraction $(p=0.08)$. There was no significant change in venous filling index $(p=0.54)$ or venous volume ( $p>0.5)^{1}$ (Level 2).

\section{Exercise for healing VLUs}

Although the evidence above ${ }^{1,4,5}$ suggests that strength and flexibility exercises are associated with improvements in measures of venous function, this may not translate to improved healing of VLUs. Evidence from small studies, ${ }^{2,}$ ${ }^{4-6}$ generally with good adherence rates ${ }^{2,5}$ and follow-up of between 12 weeks $\mathrm{s}^{4-6}$ and 12 months $^{2}$ has not demonstrated improvements in VLU healing.

The largest RCT ( $n=35)$ investigated the effect of a 10,000 steps per day walking program on VLU healing. The percent of VLUs completely healed at 12 weeks was not significantly different to VLUs that healed in a non-exercise group (83\% versus $76 \%, p=0.128) .{ }^{6}$ However, there was a significant relationship between the number of daily steps taken and VLU healing time $(p=0.08)$. Lack of significant improvements in overall healing rates may have been influenced by the low rate of success (33\% of participants) in reaching the daily goal of 10,000 steps ${ }^{6}$ (Level 1).

The RCT by Jull et. al. (2009) ${ }^{4}$ (see above) that evaluated progressive resistance exercises compared to no exercise, also reported VLU healing outcomes. There were no significant differences in changes in VLU size for individuals who participated in the exercise program compared to the control $(p=0.13)$. There was also no difference between the groups for time to complete healing (odds ratio [OR] 0.55 , $95 \% \mathrm{Cl} 0.16$ to 1.95$)^{4}$ (Level 1).

Similarly, the RCT by O'Brien et. al. (2013) $)^{5}$ (see above) that reported on a heel raise program found no condition measured using the Pressure Ulcer Scale for Healing (PUSH) $(p=0.35)$ (Level 1).

Another RCT $(n=39)^{2}$ evaluated the feasibility of a 12-week (36 sessions) supervised exercise program consisting of aerobic, resistance and flexibility exercises for individuals with VLUs. In this study, the exercise group experienced a higher VLU healing rate ( $83 \%$ versus $60 \%$ at 12 months) and a shorter median time to healing (13 (3.9 to 52) vs. 34.7 (4.3 to 52) weeks). However, statistical significance of healing outcomes was not evaluated ${ }^{2}$ (Level 1).

\section{METHODOLOGY}

This evidence summary is based on a structured database search using variations of the search terms describing VLUs and exercise. Searches were conducted in EMBASE, Medline, AMED and the Cochrane Library for evidence from 1990 to Nov 2019 in English. Where high level evidence was available, lower level evidence was not reviewed.

\section{REFERENCES}

1. Kan $Y$, Delis K. Hemodynamic effects of supervised calf muscle exercise in patients with venous leg ulceration: a prospective controlled study. Arch Surg, 2001;136(12):1364-9. (LeNov 2019. (Level 2)

2. Klonizakis M, Tew GA, Gumber A, Crank H, King B, Middleton G, Michaels JA. Supervised exercise training as an adjunct therapy for venous leg ulcers: a randomized controlled feasibility trial. $\mathrm{Br} \mathrm{J}$ Dermatol, 2018;178:172-82. (Level 1.c).

3. Szewczyk MT, Jawień A, Cwajda-Białasik J, Cierzniakowska K, Mościcka P, Hancke E. Randomized study assessing the influence of supervised exercises on ankle joint mobility in patients with venous leg ulcerations. Arch Med Sci 2010;6(6):956-63. (Level 1.c).

4. Jull A, Parag V, Walker N, Maddison R, Kerse N, Johns T. The PREPARE pilot RCT of home-based progressive resistance exercises for venous leg ulcers. J Wound Care, 2009;18(12):497-503. (Level 1.c).

5. O'Brien J, Edwards H, Stewart I, Gibbs H. A home-based progressive resistance exercise programme for patients with venous leg ulcers: A feasibility study. Int Wound J, 2013. August;10(4):389-96. (Level 1.c). 
6. Meagher H, Ryan D, Clarke-Moloney M, O'Laighin G, Grace PA. An experimental study of prescribed walking in the management of venous leg ulcers. Journal of Wound Care, 2012;21(9):421-2, 4-6, 8 passim. (Level 1.c).

7. O'Meara S, Cullum N, Nelson EA, Dumville JC. Compression for venous leg ulcers. Cochrane Database Syst Rev, 2012(11). (Level 1.a).

8. Palfreyman S, Nelson EA, Michaels JA. Dressings for venous leg ulcers: systematic review and meta-analysis. BMJ, 2007;335(7613):244-56. (Level 1.b).

9. O'Brien JA, Edwards HE, Finlayson KJ, Kerr G. Understanding the relationships between the calf muscle pump, ankle range of motion and healing for adults with venous leg ulcers: a review of the literature. Wound Practice \& Research, 2012;20(2):80-5. (Level 5.a).

10. Ricci S, Moro L, Incalzi RA. The foot venous system: Anatomy, physiology and relevance to clinical practice. Dermatol Surg, 2014. March;40(3):225-33. (Level 5.c).

11. Yim E, Richmond NA, Baquerizo K, Van Driessche F, Slade HB, Pieper $B$, Kirsner RS. The effect of ankle range of motion on venous ulcer healing rates. Wound Repair Regen, 2014. July-August;22(4):492-6. (Level 1.a).

12. Kahn SR, Shrier I, Shapiro S, Houweling AH, Hirsch AM, Reid RD, Kearon C, Rabhi K, Rodger MA, Kovacs MJ, Anderson DR, Wells PS. Six-month exercise training program to treat post-thrombotic syndrome: A randomized controlled two-centre trial. CMAJ, 2011. 11 Jan;183(1):37-44. (Level 1.c).

13. Williams KJ, Ayekoloye O, Moore HM, Davies AH. The calf muscle pump revisited. J Vasc Surg Venous Lymphat Disord, 2014. July;2(3):329-34. (Level 1.a).

14. Padberg F, Johnston M, Sisto S. Structured exercise improves calf muscle pump function in chronic venous insufficiency: A randomized trial. J Vasc Surg, 2004;39(1):79-87. (Level 1.c).

\section{THANK YOU}

On behalf of the Editorial Board, Editor Allison Cowin sincerely thanks all reviewers who contributed to the manuscripts that were published this year in Volume 27.

Thank you to Donna Angel, Judith Barker, Melinda Brooks, Ann Marie Dunk, Helen Edwards, Kathleen Finlayson, Nicoletta Frescos, Emily Haesler, Sharon Latimer, Matthew Malone, William McGuiness, Wendy Mclnnes, Charne Miller, Stuart Mills, Sue Monaro, Rachael Murray, Jane O'Brien, Rajna Ogrin, Christina Parker, Jenny Prentice, Anne Purcell, Aswathy Ravindran Girija, Robyn Rayner, Alicia Spacek, Geoff Sussman, Terry Swanson, Peta Tehan, Sue Templeton, Patrik Tosenovsky and Michael Woodward.

Special thanks to those who reviewed multiple manuscripts. The voluntary contribution that each reviewer makes contributes greatly to the high standards that Wound Practice and Research strives to achieve.

Thanks also to Emily Haesler and Robin Watts for presenting and coordinating the Evidence Summaries throughout the year.

\section{+ Better Outcomes}

\section{UK's NICE medtech guidance supports adopting PICO to reduce surgical site complications across various surgical specialties.}

\author{
$\mathrm{PICO} \diamond 7$ \\ Single Use Negative Pressure \\ Wound Therapy System
}

\section{Smith+Nephew}

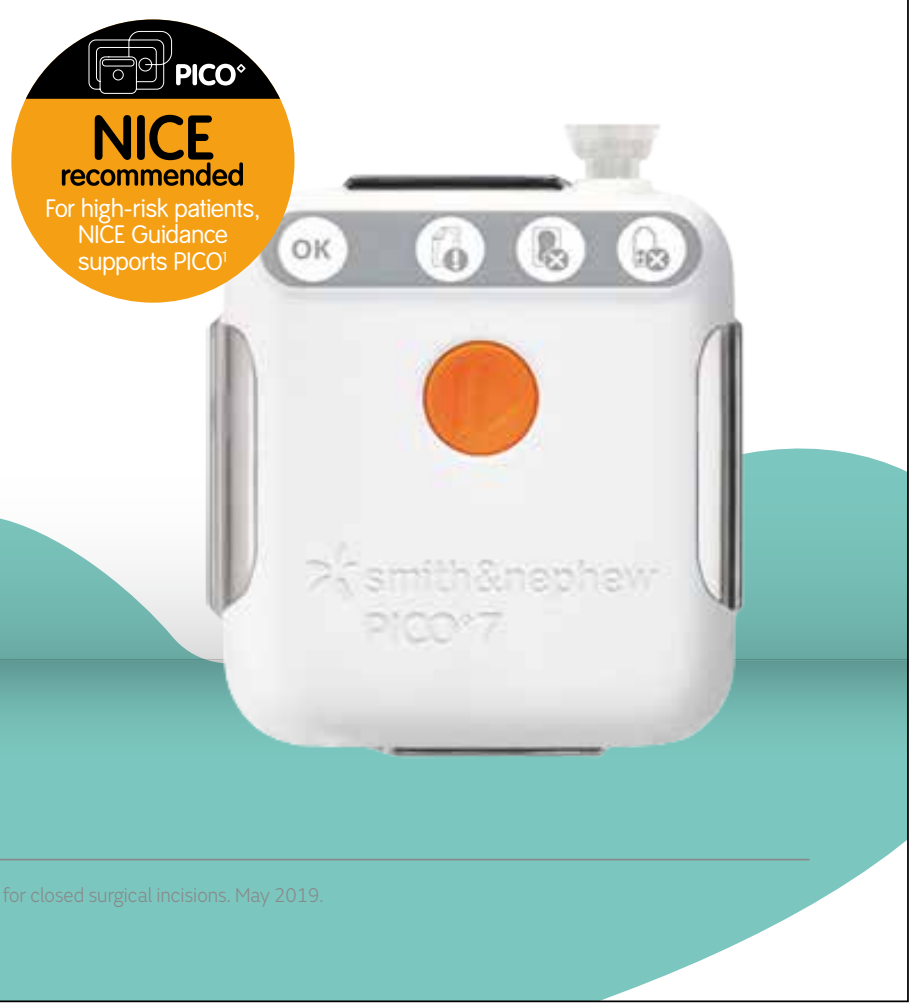

